\title{
Lower forest-grassland ecotones and 20th Century livestock herbivory effects in northern Mongolia
}

\author{
Temuulen Tsagaan Sankey*, Cliff Montagne, Lisa Graumlich, Rick Lawrence, Jerry Nielsen \\ Land Resources and Environmental Sciences Department, Montana State University, Bozeman, MT 59717, United States \\ Received 13 January 2006; received in revised form 26 May 2006; accepted 28 May 2006
}

\begin{abstract}
We studied five lower forest-grassland ecotones in the Darhad Valley in northern Mongolia and investigated the effects of 20th Century grazing regimes and changes in grazing management on ecotone dynamics at a local scale. A total of 2968 Siberian larch (Larix sibirica) trees were cored and tree-age distribution was constructed to determine 20th Century tree establishment. Tree age and location within the ecotones were correlated and seedling density and their distribution were explored to describe forest-grassland ecotone shift. To examine livestock herbivory effects on ecotone shift, the number of new trees was analyzed with five different grazing regimes and changes in grazing practices during the last 80 years in the Darhad Valley.

We documented some evidence of ecotone shift into the adjacent grassland. Rates and patterns of ecotone shift varied with different grazing regimes. Siberian larch tree establishment was greater at overall grazing intensities of low and high levels, which were dominated by sheep and cattle grazing. In contrast, larch establishment was lower at overall grazing intensities of low and medium levels, which were dominated by goat grazing. Twentieth Century changes in grazing practices also influenced Siberian larch regeneration. An abrupt decline in Darhad Valley larch establishment during the 20th Century coincided with locally increased grazing pressure. Furthermore, regional climate variability showed important interaction with local grazing regimes in affecting larch regeneration. A 20th Century pulse in larch establishment coincided with a time period of regionally known warmer temperatures and locally reduced grazing pressure. Our results suggest that overall grazing intensity, livestock species composition, and changes in grazing patterns are important in understanding grazing effects on Siberian larch tree encroachment.

(C) 2006 Elsevier B.V. All rights reserved.
\end{abstract}

Keywords: Mongolia; Forest-grassland ecotone; Livestock herbivory; Grazing effects; Siberian larch

\section{Introduction}

\subsection{Forest-grassland ecotone shift}

Woody species encroachment into grasslands has become a global phenomenon. It has been documented in Asia, Australia, Africa, South America, and North America (Archer, 1989; Mather, 2000) and is currently attracting greater attention due to its impacts on global carbon sequestration and land surface-atmosphere interactions (Archer, 1999; Mather, 2000). Tree and shrub expansion towards the adjacent grassland has been correlated with global climate change, increased $\mathrm{CO}_{2}$, fire suppression, herbivory, and snow

\footnotetext{
* Correspondence to: GIS Center, Idaho State University, Campus Box 8130, Pocatello, ID 83209-8130, United States. Tel.: +1 360927 2257;

fax: +1 4069943933 .

E-mail addresses: tsankey@montana.edu, sankteki@isu.edu (T.T. Sankey).
}

accumulation (Cairns, 1994; Bachelet et al., 2000; Bartolome et al., 2000). In central Asia, woody species expansion into grasslands has been correlated with grazing. This expansion is proposed to be further influenced by global climate changes and increased $\mathrm{CO}_{2}$ (Christensen et al., 2004). Siberian larch (Larix sibirica), in particular, has been demonstrated to respond quickly to increased $\mathrm{CO}_{2}$, increased temperature and precipitation and is expected to broaden its ranges (Mudrik and Vil'chel, 2001).

Siberian larch forest is Mongolia's dominant forest type (Tsogtbaatar, 2004). Distributed throughout the northern and northwestern regions of the country, Mongolia's larch forest is the southern-most fringe of the Siberian taiga and borders the Mongolian grassland steppe creating numerous forest-grassland ecotones. Mongolia, a continental semi-arid country, is known as one of the five most heavily grazed places in the world (Asner et al., 2005). Forest-grassland ecotones of Mongolia, therefore, provide opportunities for studying domestic livestock grazing impact on ecotone shifts. 
We studied lower forest-grassland ecotones of five Siberian larch forest stands in the central Darhad Valley in Khuvsgul province of northern Mongolia and investigated ecotone shift using dendrochronological data. Ecotone shift, as defined in this study, includes two types of ecotone change: a shift in forest-grassland boundary location toward the adjacent grassland and an increase in tree density beneath the forest canopy adjacent to the grassland. These two types of ecotone change have been documented in northwestern USA and can occur simultaneously (Arno and Gruell, 1986). Our objectives were: (1) to explore the age and spatial distribution of trees and seedlings along lower forest-grassland ecotones in the Darhad Valley; and (2) to examine the effects of local grazing regimes on tree establishment and their distribution within the ecotone. Two questions were of primary interest: (1) Are the lower forest-grassland ecotones shifting in the Darhad Valley? (2) If so, do different grazing regimes lead to different rates and patterns of ecotone shift? We also considered the effects of abiotic factors of topographic aspect and slope on subsequent variation in ecotone shift within each grazing regime.

\subsection{Grazing management changes in Mongolia}

Extensive livestock production has been Mongolia's major industry for centuries. Traditional nomadic herding lifestyle and Mongolia's expansive rangelands sustain this industry even in today's market economy. Mongolia's current livestock population is over 30 million and consists of cattle (which includes cows, yaks, and cow-yak hybrid breed), sheep, goats, horses, and camels (Agriteam, 1997). The livestock population reached its peak in the last decade along with increasing number of herders. Mongolia's livestock population was substantially smaller at the beginning of the 20th Century. It continually increased throughout the last century despite the dramatic institutional, political, and economic changes that took place in Mongolia.

A majority of Mongolia's livestock was owned by religious leaders in a few large herds until the early 20th Century. As a result of the 1921 revolution, Mongolia became a socialist country and all of Mongolia's livestock were distributed more evenly in small privately owned herds. In late 1950s, the Mongolian government established livestock collectives throughout the country and all herders had joined the collectives by 1960 (Fernandez-Gimenez, 2002). All of Mongolia's livestock then became state-owned and herders were paid a regular salary by the government to herd the livestock. The collective administration allocated pastures and regulated pasture use by forming middle-large sized herds that were moved on a seasonal basis (Fernandez-Gimenez, 2002). In 1992, Mongolia became a democratic country and started the transition to a market economy. The collectives were dismantled and the state-owned livestock were privatized. Currently, all livestock are privately owned and all herders have a constitutional access to all of Mongolia's rangelands, which are publicly owned. All Mongols have a birthright to herding livelihood, which allowed urban dwellers to migrate to the countryside during the economic transition in early 1990s
(Fernandez-Gimenez, 2002). This study examined the effects of the changes in grazing patterns and practices, associated with the institutional and economic changes of the past 80 years, on ecotones.

\subsection{Grazing animals in the Darhad Valley}

The grazing animals in the Darhad Valley are cattle, horses, sheep, and goats. Forage preferences between these animal species have been known to be substantially different (Vallentine, 2001). This difference results from the differences in body size, reticulo-rumen capacity, anatomy of teeth, lips, and mouth structure, grazing ability, agility, and digestive systems of the different species (Vallentine, 2001). Grazing animals can be divided into three groups based on their forage preferences: (1) grazers; (2) intermediate feeders; (3) browsers. Grazers primarily consume graminoids and strongly avoid woody species. Grazers occasionally consume locally available forbs and woody species when graminoids are not available. Intermediate feeders eat large amounts of graminoids, forbs, and woody species. They are known for their ability to adjust their feeding habits to whatever is locally available. Browsers primarily consume forbs and woody species and commonly consume green grass during growing seasons, but avoid dry, mature grass (Vallentine, 2001).

Horse and cattle are grazers (Vallentine, 2001). Horses mostly consume graminoids and occasionally use forbs and woody species. Cattle also prefer grasses and use forbs and woody species seasonally. Cattle can switch to woody species or forbs if grasses are not available. Sheep are intermediate feeders. They are known to be highly selective foragers. Sheep consume large amounts of forbs and grasses and lesser amount of woody species. They consume greater proportion of grasses in their diet than goats do (Gordon and Illius, 1992).

Most studies agree that goats are browsers, although they consume grasses and forbs (Gordon and Illius, 1992). Goats prefer leaves and tender twigs of woody species and consume young growth of many woody species that are less palatable to other species (Vallentine, 2001). They can consume needle leaves of conifer trees up to $220 \mathrm{~cm}$ tall by bending down the trees to reach the leaves on higher branches (Child et al., 1992). Goats are recommended to be used to reduce tree and shrub competition in rangelands. Goat grazing is often restricted in tree plantations where tree seedlings are short or thin enough to be bent over by goats (Child et al., 1992).

\subsection{Siberian larch (Larix sibirica)}

The genus Larix Miller (Pinaceae family) is distributed in North America, Asia, and Europe. The boreal Larix species, including Larix sibirica, are deciduous and occupy a wide range of habitats. Deciduousness, intolerance to shade, efficient nitrogen and carbon use, and the ability to establish on poor soils enable Larix species to be dominant at treelines (Lepage and Basinger, 1992). Larch germination and seedling establishment are negatively impacted by shading, litter cover, lack of 
soil moisture, and insolation. Drought and herbivory cause a high rate of seedling mortality (Oswald and Neuenschwander, 1992). Larch forests are known to be fire-dependent (DeByle, 1981). The deciduousness makes larch highly palatable to herbivores. In Mongolia, domestic livestock grazing is reported to be one of the three major causes of Siberian larch forest decline (Tsogtbaatar, 2004). Young, dense stands of larch trees have been known to form creating a fringe along the forest edge following a reduction in grazing pressure (Didier, 2001). We explored the 20th Century larch regeneration patterns in the Darhad Valley to determine if they coincided with changes in local grazing regimes.

In the northwestern USA, 20th Century fire suppression has been proposed as a possible cause of widely documented forest expansion (Arno and Gruell, 1986; Dando and Hansen, 1990). Fire has been shown to be a primary factor that creates and maintains grasslands (Arno and Gruell, 1986; Dando and Hansen, 1990; Covington and Moore, 1994; Mast et al., 1997; Archer, 1999). When fire is suppressed, trees encroach into grasslands (Arno and Gruell, 1986; Dando and Hansen, 1990; Covington and Moore, 1994) through increased tree seedling establishment (Mast et al., 1997; Archer, 1999) and survival (Dando and Hansen, 1990; Archer, 1999). Once seedlings reach a sufficient size and age, they are able to tolerate fires and dominate grasslands (Archer, 1999). The larch forests at our study sites are isolated small stands in the center of the valley. Although the expansive, continuous forest stands that surround the valley have high fire frequency, these isolated small stands were likely excluded from fire disturbance because of their location in continuously grazed grasslands with low fuel accumulation. The surrounding grassland areas are annually used as campgrounds and fire is likely to be suppressed in the densely populated center of the valley. We attempted to control for differences in fire history among our sites and limited our sites to those that had not burned for the last several decades. We did not find recent fire scars at our sites during our field work $(2003,2004)$.

\section{Methods}

\subsection{Study sites}

The Darhad Valley is a remote, undeveloped region in Khuvsgul province surrounded by mountains that reach $3000 \mathrm{~m}$ elevation. The valley itself is at $1650 \mathrm{~m}$ elevation and experiences extreme continental climate with cold winters and short summers. Annual precipitation ranges between 250 and $350 \mathrm{~mm}$ and mostly falls in August and September. Winter and spring months are dry with limited precipitation. The main industry in the valley is livestock production. A majority of the valley's residents are nomadic herders, who utilize the valley's public land to graze their cattle, sheep, goats, and horses. The central Darhad Valley is grazed by livestock during the summer season only (Mishig, 2004; Buya, 2004). Information from our interviews indicates no substantial differences in wildlife use throughout the valley (Buya, 2004). Wild ungulates are rarely seen in the valley (Mishig, 2004).
To study livestock grazing impact on lower forest-grassland ecotone, we selected five ecotones at five sites in the central Darhad Valley. The selected sites were all within a close geographic proximity of $5-15 \mathrm{~km}$ to each other. Each site provided an average of a $3 \mathrm{~km}$ long ecotone on small hills away from the major mountain ranges. These sites were carefully selected to represent five different grazing regimes and, at the same time, to minimize differences in physiographic and climatic variables. The five grazing regimes differed both in herd composition and herd size. The grazing regime at each site, therefore, was determined both in terms of the dominant animal species and the overall grazing intensity (Table 1). This was based on a detailed survey of the number of animals by species of every household (187 households) that has lived within $5 \mathrm{~km}$ of the ecotone during and since the collective period (1959-2004), reviews of the local government records, and interviews about the pre-collective grazing history (19211959). Many of the 187 households in the survey were interviewed regarding their current grazing practices and patterns. Five elder herders and two veterinarians were interviewed about the pre-collective grazing history. Both the herd size and composition changed over time at our study sites and have become more similar among sites over the last decade (Table 1), with increased average numbers of cattle and goat per household. Until 1921, the valley's livestock were distributed in few large herds. They were re-distributed into small herds from 1921 to 1959 , resulting in locally less intensive grazing regimes. In 1959, livestock were re-grouped into few large herds, which were divided into small herds again after 1992.

We characterized the collective period herd composition at our five sites through Principal Component Analysis (PCA) to illustrate the differences among our sites in the grazing animal species. Both herd composition and herd size remained stable at all of our sites during this period. This was also a time period when the traditional difference in herd composition among our sites was greatest. Our PCA used number of animals by species, at each site, of this period. The first principal component largely represented a gradient from sheep-dominated to cattledominated sites. An inverse relationship between sheep $(-0.61)$ and cattle $(+0.60)$ was observed indicating that high values of cattle were associated with low values of sheep. Sites 1 and 5 were dominated by sheep, while Site 4 was dominated by cattle. The second principal component represented a gradient in goat numbers. Goat numbers were also inversely

Table 1

Number of animals during the three different grazing regimes at our sites

\begin{tabular}{|c|c|c|c|c|c|c|c|c|c|}
\hline \multirow[t]{2}{*}{ Sites } & \multicolumn{3}{|c|}{$\begin{array}{l}\text { Pre-collective } \\
\text { period (1922-1959) }\end{array}$} & \multicolumn{3}{|c|}{$\begin{array}{l}\text { Collective } \\
\text { period (1959-1992) }\end{array}$} & \multicolumn{3}{|c|}{$\begin{array}{l}\text { Post-collective } \\
\text { period (1992-2004) }\end{array}$} \\
\hline & Sheep & Goat & Cattle & Sheep & Goat & Cattle & Sheep & Goat & Cattle \\
\hline Site 1 & 1500 & 250 & 100 & 3033 & 528 & 119 & 614 & 318 & 400 \\
\hline Site 2 & 840 & 500 & 130 & 1679 & 1007 & 266 & 118 & 756 & 731 \\
\hline Site 3 & 355 & 260 & 370 & 712 & 528 & 726 & 1032 & 750 & 850 \\
\hline Site 4 & 60 & 40 & 380 & 117 & 81 & 765 & 601 & 402 & 981 \\
\hline Site 5 & 1700 & 150 & 90 & 3425 & 319 & 178 & 3114 & 905 & 857 \\
\hline
\end{tabular}


Table 2

Long-term averages of grazing intensity at our sites

\begin{tabular}{|c|c|c|c|c|}
\hline Sites & $\begin{array}{l}\text { Overall } \\
\text { grazing } \\
\text { intensity }\end{array}$ & $\begin{array}{l}\text { Overall grazing } \\
\text { intensity } \\
\text { (AUM/ha) }\end{array}$ & $\begin{array}{l}\text { Dominant } \\
\text { livestock } \\
\text { species }\end{array}$ & $\begin{array}{l}\text { No. of } \\
\text { households } \\
\text { at the site }\end{array}$ \\
\hline Site 1 & Very low & 3.3 & Sheep & 20 \\
\hline Site 2 & Low & 4.2 & Goat-sheep & 32 \\
\hline Site 3 & Medium & 4.8 & Cattle-sheep-goat & 56 \\
\hline Site 4 & Medium & 4.9 & Cattle & 36 \\
\hline Site 5 & High & 5.9 & Sheep & 43 \\
\hline
\end{tabular}

related with cattle numbers $(-0.56)$ indicating that high values of cattle were associated with low values of goat. Sites 1-3 were characterized by greater numbers of goats compared to the rest of the sites. Site 2 had the highest number of goats. Number of horses varied little among the sites and among different time periods. We, therefore, did not include horses in our site characterization by species.

We estimated the overall grazing intensity at each site by calculating the long-term average of the grazing levels in total animal unit months per ha (AUM/ha) (Table 2). We then ranked the sites Site 1-Site 5 (Table 2). Site 1 represented sheepdominance and very low grazing intensity. Site 2 represented goat-sheep-dominance and low grazing intensity. Site 3 represented cattle-sheep-goat mix and medium grazing intensity. Site 4 represented cattle-dominance and medium grazing intensity. Site 5 represented sheep-dominance and very high grazing intensity (Table 2 ). We were not able to separately control for differences in herd composition and herd size due to the spatial and temporal extent of our study.

\subsection{Field methods}

A total of 149 belt transects were established at the five ecotones with 30 belt transects at four sites and 29 at one site. Belt transects were located at fixed intervals along each ecotone (20-60 m depending on the length of the ecotone) perpendicular to the ecotone. All belt transects were $5 \mathrm{~m}$ wide with varied lengths of 11-144 m depending on the width of the ecotone. The width of the ecotone was determined by the definition of ecotone used in this study: a transition zone between $80 \%$ tree canopy cover in the forest and $100 \%$ herbaceous cover in the adjacent grassland. The forest end of each belt transect was positioned at $80 \%$ mature tree $(\geq 80$ years old) canopy cover, which was ocularly estimated. Each belt transect extended from the forest into the adjacent grassland. The grassland end was positioned at $100 \%$ herbaceous cover and included the farthest out tree seedling. Slope and aspect of each belt transect were measured and recorded. All adult trees within each belt transect were mapped and cored at $30 \mathrm{~cm}$ above ground with an increment borer to estimate age. Distance of each tree from the forest end of each belt transect was measured to correlate adult tree-age estimate and distance of each tree from the forest end of the belt transects. All stems $\leq 8 \mathrm{~cm}$ in diameter at coring height were classified as seedlings. All live seedlings were counted and mapped in $5 \mathrm{~m} \times 5 \mathrm{~m}$ quadrats within each belt transect. Dead stems and cut stumps

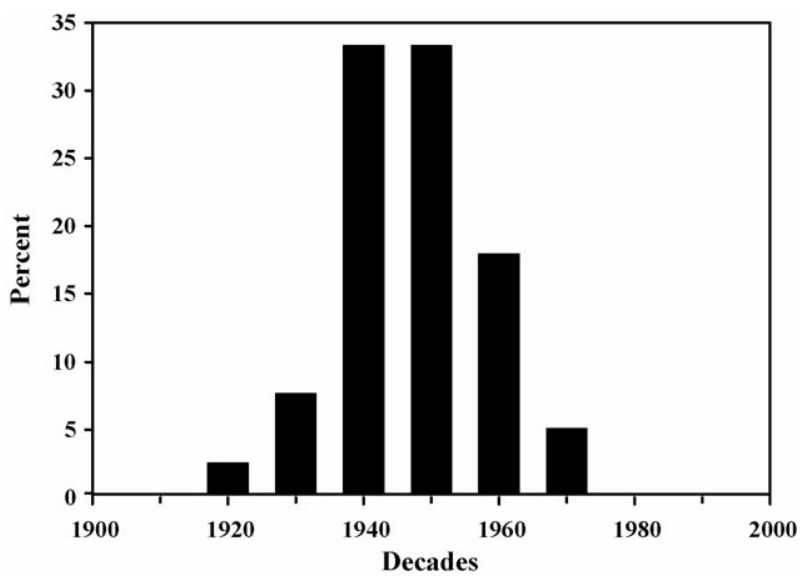

Fig. 1. Seedling-age distribution. The seedling age ranges from 29 to 80 years. A majority of these stems were established in the decade of 1940 and 1950, and no new seedlings were established after the decade of 1970. These stems were classified as seedlings and were not included in the adult tree-age distribution.

were also counted and mapped in each belt transect to estimate mortality and to compare historic fuel wood use levels among sites. Current level of cutting was not estimated because cutting is now prohibited at our sites.

\subsection{Tree-age estimate}

We cored 2968 trees and processed and dated the core samples using standard dendrochronological methods (Stokes and Smiley, 1968). A total of 2790 samples were dated successfully and 178 samples were eliminated from the analysis because of rotten wood and branch scars in the samples. A total of 4709 seedlings were counted. We destructively sampled 40 seedlings at the base of the stem to build a seedling-age distribution (Fig. 1). The same seedling samples were also used to estimate the number of rings lost from ground level to coring height of $30 \mathrm{~cm}$. Rings in the seedling samples were counted at the base of the stem and at $30 \mathrm{~cm}$ above ground. The mean difference in the number of rings at these two heights was the estimate of number of rings lost from ground level to coring height. This mean was estimated to be 11 years and was added to the tree ring count of each adult tree sample to adjust for the coring height $(30 \mathrm{~cm}$ above ground). This approach in estimating number of rings lost at coring height was assumed to be a more accurate estimate than a diameter and height regression approach because our coring height was consistently at $30 \mathrm{~cm}$ above ground.

\subsection{Data Analysis}

We first constructed tree-age distribution for each site at a decadal scale to determine if new trees established during the study period within the ecotone. New tree establishment could indicate either or both types of ecotone change: ecotone location shift and tree density increase along the ecotone. We were, therefore, interested in exploring if a relationship existed between tree age and tree location within the ecotone. If ecotone location was shifting, we would expect a process of 
new tree establishment closer to the grassland. We were interested in describing this particular process, although many ecological processes could impact tree regeneration and mortality patterns along the ecotone and make this process difficult to distinguish. We examined adult tree-age estimate with the distance of trees from the forest end of the plots and used a regression model. The regression model also included the five sites as indicator variables and interaction terms of tree distance and sites to reduce the error effects caused by site differences and to test for differences between sites. This analysis included the adult trees only.

We then examined the seedling distribution along the ecotone to further explore ecotone shift. Ecotones at our study sites appeared to be shifting into the adjacent grassland in pulses over time. The pattern of seedling establishment along the edge of the forest at the sites appeared very similar to the "fairy ring" establishment documented in northwestern USA in species such as aspen (DeByle and Winokur, 1985). The fairy ring regeneration is associated with a pulse regeneration of stems of similar age and size. If such regeneration is occurring in the adjacent grassland along the edge of the forest, the ecotone would be shifting into the adjacent grassland in pulses over time. We were, therefore, interested in quantitatively describing the seedling distribution within the ecotone. Specifically, we were interested in determining if seedling density varied throughout the ecotone from the grassland end of the belt transects to the forest end of the belt transects. We expected to find a peak in average seedling density midway between the full canopy forest and the grassland end of the ecotone, if seedlings were regenerating in a pulse forming a "fairy ring" along the forest boundary. We examined the average seedling density per quadrat with the quadrat distance from the grassland end of the belt transects using a regression model. Average seedling density was the response variable and quadrat distance was the predictor variable. Sites and interaction terms of sites and quadrat distance were added in the model as predictor variables. However, these variables were statistically insignificant as predictors. They were, therefore, excluded from our final model, which included only quadrat distance and a squared term as predictor variables.

We performed a one-way ANOVA test to examine grazing effects on ecotones. The percentage of new stems established in the last 80 years was the response variable and the grazing regime was the predictor variable. Tukey's multiple comparison was used with all pairs to determine where significant differences occurred. We constructed a regression model to
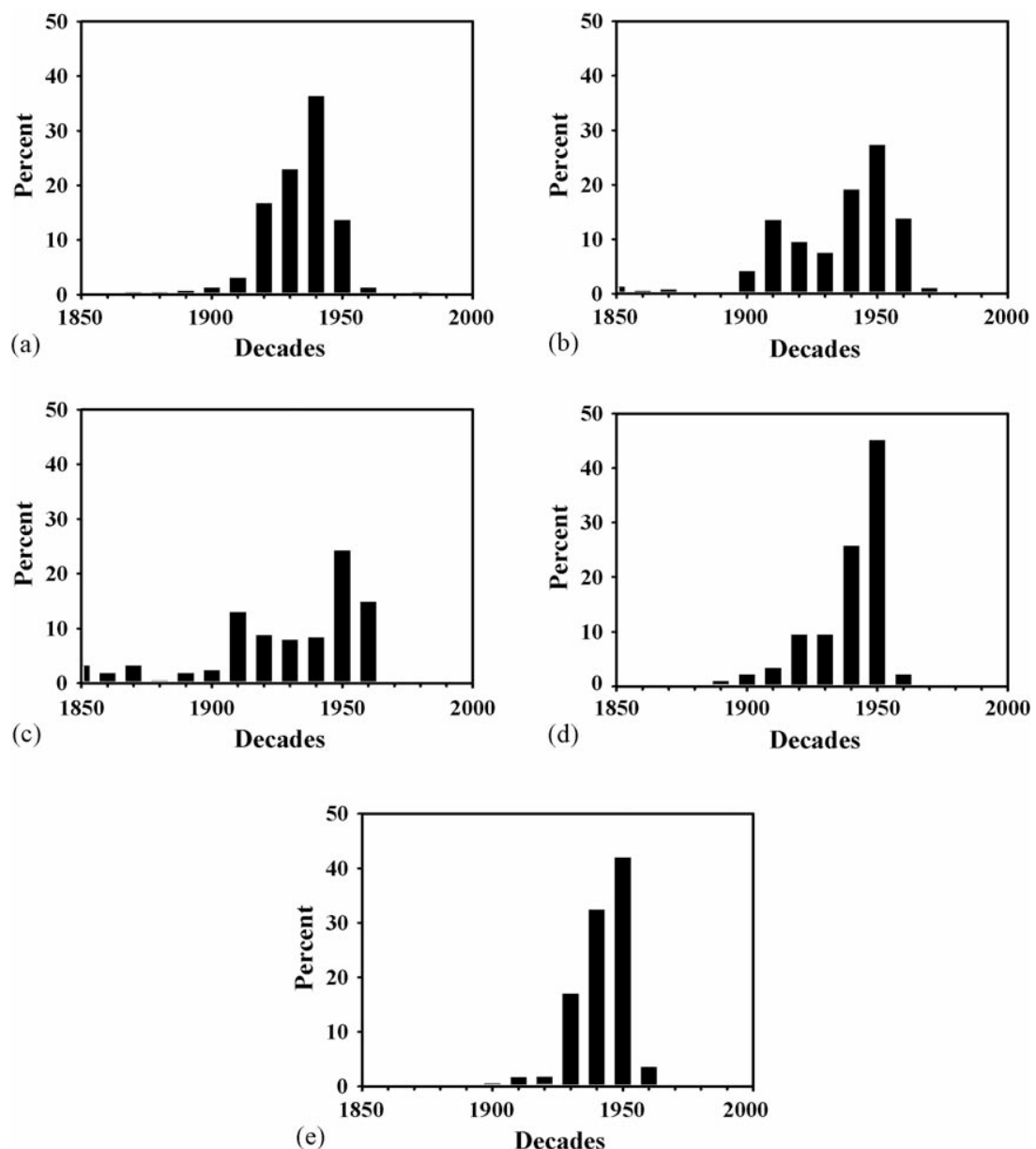

Fig. 2. Adult tree-age distribution at a decadal scale at Site 1-Site 5 (a-e). Up to $95 \%$ of the adult trees were new trees that established within the last 80 years. All sites show a pulse of regeneration in the decades of 1930, 1940, and 1950, but no new tree establishment after the decade of 1960. 
determine if topographic aspect and slope explained further variation in tree establishment within each grazing regime. Slope and aspect (cos transformation) were the predictor variables in this model. The percentage of new stems was the response variable.

\section{Results}

\subsection{Forest-grassland ecotone}

Adult tree-age distribution was constructed at a decadal scale (Fig. 2(a-e)). The tree-age distribution indicated that up to $95 \%$ of the adult trees were new trees that established within the last 80 years. An additional 4709 stems were counted as seedlings. The seedling-age estimate indicated that the age of these stems ranged from 29 to 80 years (Fig. 1). The seedlingage distribution indicated that a majority of these stems were as old as the stems that were cored and classified as adult trees. However, the stems classified as seedlings were too small in size ( $\leq 8 \mathrm{~cm}$ in diameter at coring height) and were not cored. They were not included in the adult tree-age distribution, but provided further evidence of new tree establishment in the last 80 years. Both the adult tree-age distribution and seedling-age distribution show high rates of tree establishment during the decades of 1930, 1940, and 1950 indicating a pulse of regeneration that occurred during this period. Both the adult tree-age distribution and seedling-age distribution show no new tree establishment after the decade of 1960 and 1970 respectively. We did not find an expected seedling establishment over the last three decades.

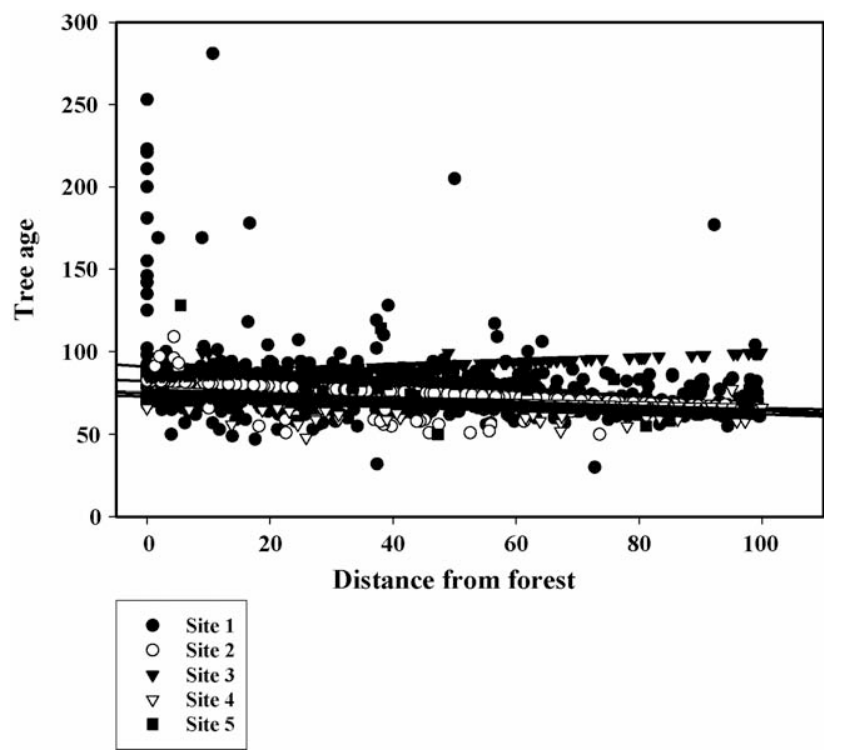

Fig. 3. Tree age and distance relationship at all sites. The estimate of tree age expressed in years is on $Y$-axis. The distance of trees from full canopy forest is on the $X$-axis and is expressed in percent. A single regression model was constructed with a separate indicator variable for each site. Regression equation is: Tree age $=90.6-(0.2 \times$ Tree distance $)-(8.3 \times$ Site 2$)-(5.6 \times$ Site 3$)-(17.1 \times$ Site 4$)-(16.6 \times$ Site 5$)+(0.1 \times$ Tree distance $\times$ Site 2$)+(0.4 \times$ Tree distance $\times$ Site 3$)+(0.2 \times$ Tree distance $\times$ Site 4$)+(0.1 \times$ Tree distance $\times$ Site 5$)$. Distance was a significant predictor variable in this model. Tree age showed a trend of decrease with increasing distance at all sites with the exception of Site 3.
We then analyzed the estimated adult tree age with tree distance from the forest end of the belt transects to describe the process of ecotone shift. We constructed a regression model (Fig. 3) which produced significant $p$-values of $<0.001$ for the model and all predictor variables of distance, site, and the interaction term. Tree age showed a trend of decrease with increasing distance from the forest end of the belt transects at all sites, with the exception of Site 3 , where tree age shows a trend of slight increase. This might indicate that the process of ecotone shift into the adjacent grassland was occurring at all sites with the exception of Site 3 . The regression model produced a low $R^{2}$ of 0.10 . We expected a low coefficient of determination in describing this process because many other ecological processes influence regeneration patterns along the ecotone and make this process difficult to discern. Site 3 was only marginally significantly different compared to Site 1 ( $p$ value $=0.06$ ), but Sites 2,4 , and 5 were significantly different compared to Site 1 ( $p$-values of $0.002,<0.001$, and $<0.001$ respectively). The interaction term of distance and Site 2 was only marginally significant compared to that of distance and Site $1(p$-value $=0.06)$. The interaction terms were significantly different for Sites 3-5 compared to the interaction term for Site 1 ( $p$-values of $<0.001,<0.001$ and 0.001 respectively). The slope of the regression lines varied significantly among different sites. This indicated that the rates and patterns of ecotone shift might be different among sites.

Next, we analyzed average seedling density with quadrat distance from the grassland end of the belt transects through a regression model to further explore potential ecotone shift and to determine if successful seedling establishment varied within the width of the ecotone. This test produced an $R^{2}$ of 0.43 and significant $p$-values of $<0.001$ for both predictor variables and the model. Average seedling density at the grassland end of the belt transects appeared to be close to zero, since the grassland end of our belt transects were located at $100 \%$ herbaceous

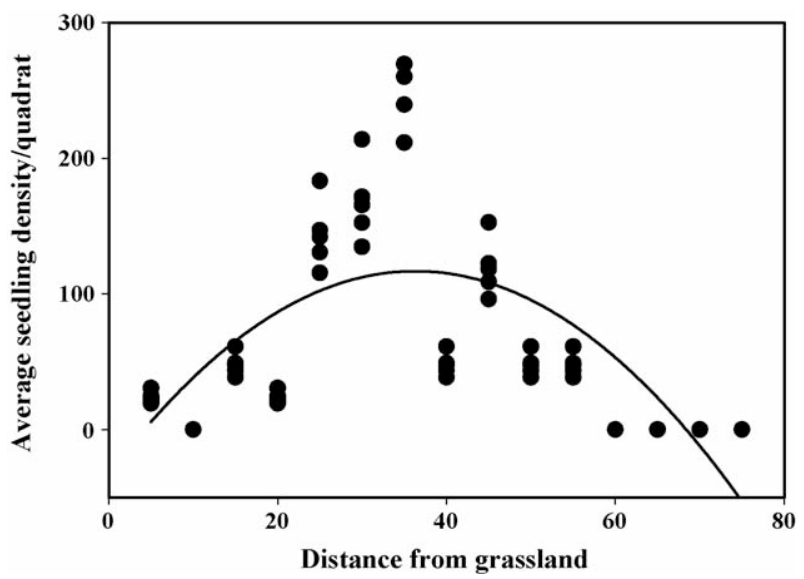

Fig. 4. Seedling distribution within the ecotone. Regression equation is: average seedling density $=\beta_{0}+\beta_{1} \times$ quadrat distance + (quadrat distance) $\times 2$. The distance from grassland on $X$-axis was measured in meters. $Y$-axis indicates average seedling density per quadrat in all belt transects. Average seedling density increases starting at $5 \mathrm{~m}$ from the grassland end of the plots at $100 \%$ herbaceous cover and peaks midway between the grassland and full canopy forest. This peak indicates a higher rate of seedling establishment outside of the full canopy forest that resulted in the "fairy ring". 


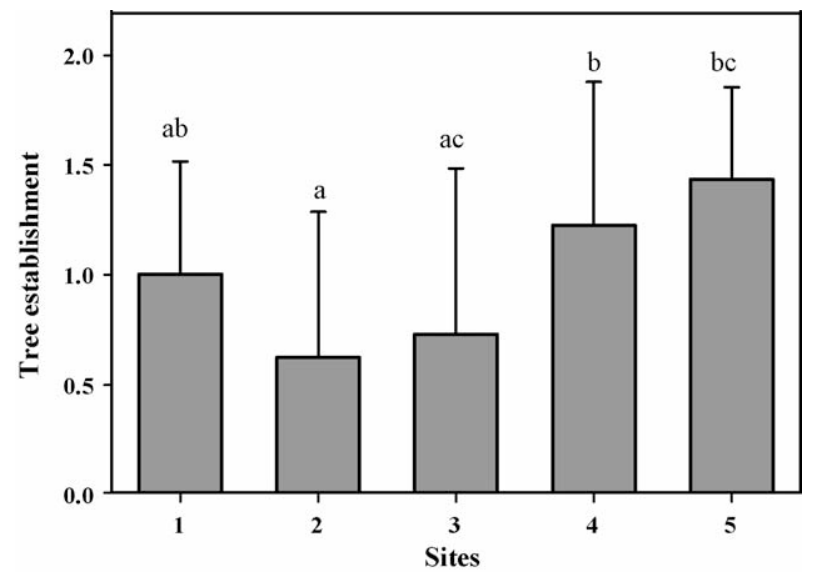

Fig. 5. Tree establishment with different grazing regimes. The five sites with different grazing regimes are on the $X$-axis. Tree establishment on $Y$-axis (expressed in percent) was estimated with the number of new trees established each year over the last 80 years. Site 2 had significantly lower tree establishment than Site 5. Sites 2 and 3 also had significantly lower tree establishment than Site 4 .

species cover. Starting at approximately $5 \mathrm{~m}$ from $100 \%$ herbaceous species cover, a few seedlings were found. These smaller distances from the grassland represented distances at which the farthest out seedlings were found outside of the fairy ring. Average seedling density increased from these distances and peaked at approximately $35 \mathrm{~m}$ and then decreased with increasing quadrat distance from the grassland end of the belt transects towards the full canopy forest (Fig. 4).

\subsection{Grazing impact on ecotones}

We performed a one-way ANOVA to examine the effects of different grazing regimes on tree establishment. The grazing regimes were a statistically significant predictor variable $(p$ value $<0.001)$ (Fig. 5). The number of new stems established varied significantly between Site 2 (goat-sheep-dominated and low overall grazing intensity) and Site 4 (cattle-dominated and medium overall grazing intensity) and between Site 2 (goatsheep-dominated and low overall grazing intensity) and Site 5 (sheep-dominated and high overall grazing intensity) (Fig. 5). The number of new stems established also varied between Site 3 (cattle-sheep-goat mix and medium overall grazing intensity) and Site 4 (cattle-dominated and medium overall grazing intensity). There was no statistically significant difference between Site 3 (cattle-sheep-goat mix and medium overall grazing intensity) and Site 5 (sheep-dominated and high overall grazing intensity) (Fig. 5) possibly due to the large variance in tree establishment at Site 3, although the two means from these sites appeared to be very different. We then constructed a regression model to determine if topographic aspect and slope explained variation in tree establishment within each grazing regime. Topographic aspect and slope were not significant predictor variables ( $p$-value of 0.61 and 0.69 respectively).

\section{Discussion}

\subsection{Forest-grassland ecotone}

Our results from three different sources indicated changes and a possible shift that might be occurring in the lower forestgrassland ecotones in the Darhad Valley. First, the ecotone treeage estimate indicated that a majority of the adult trees in the ecotone were new trees that established within the last 80 years (Fig. 2). The ecotone tree-age distribution, in most cases, was consistent with previously described age distribution of newly established, young larch forest stands (Bondarev, 1997). None of the ecotone tree-age distribution represented typical age distribution of multi-aged Siberian larch stands (Bondarev, 1997). These results suggested that the Darhad Valley ecotones were dominated by trees that established in the last few decades. The seedling-age estimate (29-80 years) provided further evidence of this age distribution pattern.

Second, the tree age and distance regression results indicated that a process of a shift in the forest-grassland ecotone location might be occurring (Fig. 3), although the regression correlation coefficient was low. Adult tree age showed a trend of decrease with increasing distance from the full canopy forest towards the adjacent grassland at all sites with the exception of Site 3. This might indicate that the younger trees were found closer to the grassland end of the ecotone, while older trees were found at the forest end of the ecotone. This trend provided an evidence of a process of a shift potentially occurring in the forest-grassland ecotones in the Darhad Valley. Similar patterns of tree encroachment into the adjacent grasslands have been documented throughout the southwestern and northwestern USA. Lower ecotones of conifer forests have been known to be shifting into the adjacent grassland in such a pattern (Arno and Gruell, 1986) due to 20th Century fire suppression, herbivory, climate change, increased $\mathrm{CO}_{2}$, and drought (Dando and Hansen, 1990; Bachelet et al., 2000; Bartolome et al., 2000; Asner et al., 2005).

Third, our analysis of seedling density and their distribution within the ecotone also indicated a potential shift in the forestgrassland ecotone location (Fig. 4). The seedling distribution, however, indicated a different pattern of ecotone shift compared to the pattern described above. Unlike the gradual shift in ecotone location towards the adjacent grassland observed in adult tree distribution, the seedling distribution indicated a pulse pattern in ecotone shift. Average seedling density was lower at the grassland end and at the forest end of the belt transects. Seedling density peaked midway between full canopy forest and $100 \%$ herbaceous species cover. There were, with a few exceptions, no older mature trees among the high-density seedlings. These patterns indicated a pulse of regeneration that resulted in "fairy rings" along the forest boundary. In a pulse regeneration process, seedling establishment in the "fairy rings" exceed the number of seedlings established beneath the forest canopy to create the distinct fringe of high density seedlings. These "fairy rings" advance the ecotone into the adjacent grassland in pulses. Interestingly, such pulse patterns in forest boundary shift have also been 
commonly observed throughout the northwestern USA in species such as aspen (DeByle and Winokur, 1985).

Our seedling density analysis also provided a quantitative description for the "fairy ring" pattern of regeneration we observed in the field. Other studies have showed that "fairy ring" regeneration is often associated with a wave regeneration mechanism (DeByle and Winokur, 1985; Bartos, 2001). During this mechanism, new stems establish in pulses creating fringes along the forest boundary in the adjacent grassland. Larch trees are known to regenerate in pulses following reductions in disturbance (Didier, 2001). Furthermore, pulses of Siberian larch regeneration in the Altai Mountain treelines, adjacent to our sites in northern Mongolia, have been correlated with warmer periods of the 1900s, 1920s, 1930s, and 1940s (Moiseev, 2002). Interestingly, a majority of the stems in the "fairy ring" regeneration and a large proportion of the adult trees were established in the decades of 1930, 1940, and 1950. The onset of this pulse regeneration at our sites coincided with the last two decades of the warmer period in the Altai Mountains (Moiseev, 2002). Another climate reconstruction study at a closer location in Mongolia showed that average temperatures increased during the decades of 1930, 1940, and 1950, but decreased during the decade of 1920 (D'Arrigo et al., 2000). This climate pattern also coincides with the pulse regeneration at our study sites and provides a possible explanation for the lesser degree of tree establishment during the decade of 1920.

\subsection{Grazing effects on ecotones}

Larch tree establishment varied significantly between different grazing regimes at different sites (Fig. 5). Our grazing regimes differed both in herd size and composition among the sites (Tables 1 and 2). Both the overall grazing intensity and livestock species composition might have contributed to the differences in tree establishment among the sites, although we could not separately control for herd size and herd composition due to the temporal and spatial extent of our study. The site with the highest goat number, Site 2, had the lowest tree establishment and statistically significantly lower tree establishment compared to Sites 4 and 5 (Fig. 5). Site 3 with goat grazing also had statistically significantly lower tree establishment than Site 4 (Fig. 5), although these two sites had very similar overall grazing intensities of medium level. These results are consistent with the conclusions of other studies that goats have negative effects on tree and tree seedling establishment (Child et al., 1992; Vallentine, 2001).

Two of the sites, Site 1 and Site 5, were dominated by sheep. Site 1 represented the lowest overall grazing intensity, whereas Site 5 represented the highest overall grazing intensity (Table 2). We found no statistically significant difference in tree establishment between these two sites. This might indicate that sheep, in general, do not have substantial negative effects on tree establishment regardless of sheep grazing intensity.

The results from all sites indicated that a majority of the new stems were established during the decades of 1930, 1940, and 1950 (Figs. 1 and 2). Interestingly, these decades coincided with the time period when livestock in the Darhad Valley were distributed in small herds. Darhad Valley's livestock were distributed in few large herds before 1920s, when the religious leaders ruled this area. After the 1921 revolution, the large herds were re-distributed into small herds. The collectives were established in the Darhad Valley in 1959 and the livestock were re-grouped into few large herds again. Our results of this pulse regeneration during the decades of small herds (1930, 1940 and 1950) were consistent with the conclusions of another study that documented the establishment of new stands of dense larch trees in fringes following a reduction in grazing pressure (Didier, 2001). These decades of small herds also coincided with the warmer periods of the 20th Century observed in this region (D'Arrigo et al., 2000). It is, therefore, difficult to say conclusively that lower grazing pressure alone caused greater tree establishment during these decades. It might be that the combination of regionally known warmer temperatures and locally reduced grazing pressure allowed trees to establish in a pulse during these decades.

The results of this study also indicated that there was an abrupt decline in tree establishment in the decade of 1960. This decline is apparent in both the adult tree-age distribution and seedlingage distribution (Figs. 1 and 2). Furthermore, none of our age distribution patterns showed successful tree establishment following this decade. The decade of 1960 (and the decade of 1970 in the case of seedings) appeared to mark the end of tree establishment of the 20th Century at these sites and coincided with the establishment of the collective. Average temperatures continued to increase throughout the decades of 1960 and 1970 in this region and remained high with increasing average temperatures in the northern hemisphere throughout the rest of the 20th Century (D'Arrigo et al., 2000). The abrupt decline in tree establishment, therefore, might be associated with the collective establishment. During the collective period, animals were re-grouped into large herds, increasing the local grazing pressure at all of our sites. The collective operation continued for over three decades and the collective only collapsed in the last decade of the 20th Century. A pulse of larch tree regeneration might occur and a fringe might be observed in the future, since the livestock are now re-distributed in small herds.

\section{Conclusion}

This study indicated that the lower forest-grassland ecotones might be shifting towards the adjacent grassland in the Darhad Valley. Siberian larch in the Darhad Valley regenerated in a pulse during the 20th Century. The pulse regeneration coincided with time periods of small herds at the sites and regionally known periods of warmer temperatures. The combined effects of regional climate variability and locally reduced grazing pressure might have contributed to the pulse regeneration. The changes in the grazing practices alone might still have important effects on ecotone shift over time. Our study showed that there was an abrupt decline in tree establishment during the 20th Century that coincided with the change in grazing patterns associated with the collective establishment. The observed changes in the ecotones also varied due to the differences in grazing regimes among sites. 
This study suggested that both overall grazing intensity and livestock species composition might be important in understanding grazing effects on tree encroachment. These results have important implications for land resource management in the face of global land cover changes. Land managers interested in controlling or promoting forest expansion into adjacent grasslands can utilize combinations of different grazing intensities and different livestock species.

\section{References}

Agriteam Canada Consulting Ltd., 1997. Study of Extensive Livestock Production Systems. Asian Development Bank, Ulaanbaatar, Mongolia.

Archer, S., 1989. Have Southern Texas savannas been converted to woodlands in recent history? Am. Nat. 134, 545-561.

Archer, S., 1999. Woody plant encroachment into southwestern grasslands and savannas: rates, patterns and proximate causes. In: Vavra, M., Laylock, W., Pieper, R.D. (Eds.), Ecological Implications of Livestock Herbivory in the West. Society for Range Management, Denver, pp. 13-69.

Arno, S.F., Gruell, G.E., 1986. Douglas-fir encroachment into mountain grasslands in southwestern Montana. J. Range Manage. 39, 272-275.

Asner, G.P., Elmore, A.J., Olander, L.P., Martin, R.E., Harris, T., 2005. Grazing systems, ecosystem responses, and global change. In: Matson, P.A., Gadgil, A., Kammne, D.M. (Eds.), Ann. Rev. Environ. Resour. 29.

Bachelet, D., Lenihan, J.M., Daly, C., Neilson, R.P., 2000. Interactions between fire, grazing and climate change at Wind Cave National Park, SD. Ecol. Model. 134, 229-244.

Bartolome, J., Franch, J., Plaixats, J., Seligman, N.G., 2000. Grazing alone is not enough to maintain landscape diversity in the Montseny Biosphere Reserve. Agric. Ecosyst. Environ. 77, 267-273.

Bartos, D.L., 2001. Landscape dynamics of aspen and conifer forests. In: Symposium Proceesings: Sustaining Aspen in Western Landscapes, RMRS-P-18, USDA Forest Service, Logan, Utah.

Bondarev, A., 1997. Age distribution patterns in open boreal Dahurican larch forests of Central Siberia. Forest Ecol. Manage. 93, 205-214.

Buya, J., 2004. Personal communication, Darhad Valley, Khuvsgul aimag, Mongolia.

Cairns, D.M., 1994. Development of a physiologically mechanistic model for use at the alpine treeline ecotone. Phys. Geog. 15 (2), 104-124.

Child, D.R., Byington, E.K., Hansen, H.H., 1992. Goats in the mixed hardwoods in the southeastern United States. In: Multispecies Grazing Proceedings, Windrock International.

Christensen, L., Coughenour, M.B., Ellis, J.E., Chen, Z.Z., 2004. Vulnerability of the Asian typical steppe to grazing and climate change. Clim. Change. 63, 351-368.

Covington, W.W., Moore, M.M., 1994. Southwestern ponderosa forest structure: changes since Euro-American settlement. J. Forestry 40, 39-47.
Dando, L.M., Hansen, K.J., 1990. Tree invasion into a range environment near Butte, Montana. Great Plains-Rocky Mount. Geog. J. 18, 65-76.

D’Arrigo, R., Jacoby, G., Pederson, N., Frank, D., Buckley, B., Nachin, B., Mijiddorj, R., Dugarjav, C., 2000. Mongolian tree rings, temperature sensitivity and reconstructions of Northern Hemisphere temperature. Holo 10 (6), 669-672.

DeByle, N.V., 1981. Clear-cutting and fire in the larch/Douglas-fir forests of western Montana: a multifaceted research summary. Gen. Tech. Rep. INT99. Intermountain Forest and Range Experimental Station. USDA Forest Service. Fort Collins, Colorado.

DeByle, N. V., Winokur, R. P., 1985. Aspen: ecology and management in the Western United States. Gen. Tech. Rep. RM-119. Rocky Mountain Forest and Research Station, Fort Collins, Colorado.

Didier, L., 2001. Invasion patterns of European larch and Swiss stone pine in subalpine pastures in the French Alps. Forest Ecol. Manage. 145, $67-77$.

Fernandez-Gimenez, M.E., 2002. Spatial and social boundaries and the paradox of pastoral land tenure: a case study from postsocialist Mongolia. Human Ecol. 30 (1), 49-78.

Gordon, I.J., Illius, A.W., 1992. Foraging strategy: from monoculture to mosaic. In: Speedy, A.W. (Ed.), Progress in Sheep and Goat Research. CAB International.

Lepage, B.A., Basinger, J.F., 1992. The evolutionary history of the genus Larix (Pinaceae). In: Symposium on Ecology and Management of Larix Forests: A Look Ahead, Whitefish, MT, USA.

Mast, J.N., Veblen, T.T., Hodgson, M.E., 1997. Tree invasion within a pinegrassland ecotone: an approach with historic aerial photography and GIS modeling. Forest Ecol. Manage 93, 181-194.

Mather, A., 2000. South-North challenges in global forestry. In: Palo, M., Vananen, H. (Eds.), World Forests from Deforestation to Transition. Kluwer Academic Publishers, Dordrecht/London/Boston.

Mishig, J., 2004. Personal communication, Darhad Valley, Khuvsgul aimag, Mongolia.

Moiseev, P.A., 2002. Effects of climatic changes on radial increment and age structure formation in high-mountain larch forests of the Kuznetsk Ala Tau. Russ. J. Ecol. 33 (1), 7-13.

Mudrik, V.A., Vil'chel, G.E., 2001. Ecophysiological responses of Larix sibirica Ledeb. and Pinus sibirica Du Tour undergrowth to climate change. Russ. J. Ecol. 32 (4), 267-273.

Oswald, B.P., Neuenschwander, L.F., 1992. Microsite characteristics and safe site description for western larch germination and initial seedling establishment. In: Symposium on Ecology and Management of Larix Forests: A Look Ahead, Whitefish, MT, USA.

Tsogtbaatar, J., 2004. Deforestation and reforestation needs in Mongolia. Forest Ecol. Manage. 201, 57-63.

Stokes, M.A., Smiley, T.L., 1968. An Introduction to Tree-Ring Dating. The University of Arizona Press, Tucson, Arizona.

Vallentine, J.F., 2001. Grazing Management. Academic Press, San Diego/San Francisco/New York/Boston/London/Sydney/Tokyo. 